\title{
Dependence of Synthesis of Protein of Edible Insects from the Nutrient Environment
}

\author{
D. A. Mirzaeva ${ }^{1}$, N. A. Khujamshukurov ${ }^{1}$, B. O. Soxibov $^{2}$, Sh. Sh. Azimov ${ }^{3}$ \\ and D. Kh. Kuchkarova ${ }^{4}$
}

${ }^{1}$ Tashkent Chemical-Technological Institute, ${ }^{2}$ Surkhandarya Regional Center for Education and Training of Public Education Workers, ${ }^{3}$ Tashkent State Technical University,

${ }^{4}$ Tashkent Architectural-Civil Engineering Institute, Uzbekistan

*Corresponding author

\section{A B S T R A C T}

\begin{tabular}{|l|}
\hline K e y w o r d s \\
Tenebrio molitor, \\
Yellow mealworm, \\
Edible insects, \\
Amino acid, \\
Lemna minor, \\
Azolla carolina \\
\hline Article Info \\
\hline Accepted: \\
26 April 2020 \\
Available Online: \\
10 May 2020
\end{tabular}

\begin{abstract}
In this article, survival coefficients of Tenebriomolitor $\mathrm{F}_{6}$ larvae were determined in three different compositions and sources of nutrients with different humidity (wheat bran, Lemna minor and flour Azollacarolina). Tenebriomolitor $\mathrm{F}_{6}$ larvae of the generation of variants TMO-2 and TMO- 6 were grown on wheat bran with an average survival rate of 0.79 , on duckweed flour -0.50 , on azolla flour - 0.64. It was noted that the survival rate of larvae grown on wheat bran was $15.5 \%$ higher than that of larvae grown on azolla, and it is advisable to explain the source not by the protein reserve, but by the amount of moisture in it. It was noted that the moisture content $(9.58-10.12 \%)$ (protein $15 \%)$ in wheat bran was a factor in the high viability of the larvae compared to azolla (protein-27\%, humidity $8.2 \%$ ). Despite the easy protein synthesis in the body of larvae in duckweed flour (protein - $16.1 \%$, humidity - 4.4\%) compared to azolla flour, its content is $3.8 \%$ lower than that of azolla, due to the fact that survival the larvae in them were lower than in wheat and azolla. Therefore, along with the protein content, moisture is an important factor when choosing a food source. When summing the survival rates of larvae of the Tenebriomolitor $\mathrm{F}_{6}$ generation in the studied nutrient media, the average survival was calculated as 0.96 . This means that based on the established ratios of wheat bran, duckweed and azolla flour, it will be possible to create a nutrient medium with a new content, high nutritional value and low cost.
\end{abstract}

\section{Introduction}

Studying the economic and environmental aspects of edible insects allows them to be widely used. In particular, the high protein supply of insects and the fact that they consume less food than other sources allow us to consider them as an economically sustainable alternative source. The production of protein products based on edible insects is explained by a high economic profitability than the production of protein products based on livestock and poultry (Van Huis., 2013).

In particular, if at least $20 \mathrm{~kg}$ of corn and soybeans are required per kilogram of beef (Smil, 2002), edible insects such as locusts will need $2 \mathrm{~kg}$ of feed to produce one kilogram of protein (Khujamshukurov, et al., 2016). At the same time, it is very important 
that edible insects consume less water than livestock (Steinfeld et al., 2006). To obtain products based on cattle, fishmeal, bone meal, sunflower, cotton and soy protein and even animal blood are added to feed products to enrich their feed composition. This leads to an increase in the cost of these feed products and a sharp decrease in their economic profitability (Қамар; Tran et al., 2015; Van Huis et al., 2013.).

When growing protein products based on edible insects, it is possible to organize the process of their environmentally friendly production compared to cattle, pigs and poultry (Khujamshukurov, 2011). The relatively low level of greenhouse gases, including methane, nitrogen oxides, and carbon dioxide, which form edible insects than livestock, play an important role in maintaining environmental sustainability (Oonincx et al., 2010). It is also possible to breed insects under controlled conditions and start a small business without attracting large amounts of money (Berggren et al., 2019). It also ensures that farms organize their own production, get high protein foods and lower their cost.

The high protein content in edible insects and the presence in them of all the necessary amino acids determine the nutritional value of the food products on which they are based. For example, one of these edible insects is the flour beetle (Tenebrio molitor), which stores protein and is rich in amino acids, including a high level of essential amino acids, such as lysine and methionine (Ekpo, 2011).

According to scientific sources, this food insect with respect to dry matter contains 40$75 \mathrm{~g} / 100 \mathrm{~g}$ of protein, $7-77 \mathrm{~g} / 100 \mathrm{~g}$ of fat and 3-8 g/100 g of minerals (Bukkens et al., 2005; Ramos-ElorduyBlasquez et al., 2012; RamosElorduy et al., 1997; Rumpold et al., 2013). Some scientific sources have shown that
Tenebrio molitor contains $51 \%$ protein, $32 \%$ fat and up to $5 \%$ minerals compared to dry matter (Zieli'nska et al., 2015).

In addition, the composition of many edible insects is rich in lipids (up to $27.4 \%$ ), which can be used to enrich various lipid-based products, to obtain lipid-based drugs, or as a source in the production of alternative sources, including biodiesel.

Studies have shown that when $20 \%$ Tenebrio molitor is added to flour for food, the lipid content increases from $0.9 \%$ to $5.4 \%$ (Azzollini et al., 2018). The composition of edible insects is also rich in fatty acids (Zhao et al., 2019). Although the vitamin retinol in edible insects is very low compared to other sources, it is very rich in vitamins such as riboflavin, pantothenic acid and biotin, which determine its nutritional value. Some studies also report high levels of folic acid (Rumpold et al., 2013).

As promising edible insects, like Schistocerca gregaria is characterized by protein content up to $76 \%$ in relation to dry matter, and tropical locusts Gryllodes sigillatus - up to $70 \%$. If we compare these figures with serum $(\sim 87 \%)$ and chicken egg protein $(\sim 82.1 \%)$, we will see that they are very important (Kamler et al., 2012).

According to the FAO, the amount of methionine and cysteine amino acids in locusts is equal to daily human consumption (Zieli'nska et al., 2015). It is also reported that the minerals in edible insects are larger in comparison with other objects, such as beef $6 \mathrm{mg} / 100 \mathrm{~g}$, in locusts $8 \mathrm{mg} / 100 \mathrm{~g}$. While the fat content in milk powder is about $26 \%$, in the beetle this indicator is about $25 \%$ (Fitzpatrick et al., 2004). The practice of obtaining protein products from edible insects and their use in poultry and fisheries has not yet become widespread in the Republic of 
Uzbekistan. There are several reasons for this:

First, as in world practice, it is difficult to study new food sources and apply them in everyday practice;

The second - the ethnic mentality of the local population is sharply affected;

Thirdly, the staff of consumer farms does not have enough information about edible insects, their importance, nutritional value, ease of production and guidelines for their use in the religious beliefs of the local population;

Fourth, the manufacturing sectors were provided with sufficient sources of production and so on.

After the independence of the Republic of Uzbekistan (1991), livestock, poultry and fishing developed rapidly, small enterprises were established, and the demand for nutritious and inexpensive food products at the local level grew several hundred times.

In particular, 600 tons of wheat used in the food industry in 2018 was allocated only to the fishing industry. The main reason for this is that, under local conditions, wheat does not stand out as a source of food and feed. In addition, high-protein crops such as barley, corn and soybeans are not grown as large plantations. In addition, fish products and their processing industry, sufficient for the production of fishmeal, are under development. In particular, it was planned to grow about 6-9 tons of fish in 1996-2009, 72 tons in 2010-2017, 82 tons in 2018, 150 tons in 2019 and about 200 tons in 2020 (Decree of the President of the Republic of Uzbekistan, 2017 ).

Therefore, one of the most important tasks is the development of the fishing industry in the local context, the creation of a continuous feed base for this industry with high nutritional and nutritional value.

It is known that a large number of food products are used in the cultivation of food insect species. These include products such as soy flour, corn flour and bran, wheat bran or cereal products, flour and bran, depending on the conditions of the region in different countries. Since these products are mainly food for human consumption, one of the important tasks is the search and study of alternative sources of their replacement.

Production based on macrophytes Lemna spp. is 60-145 t/ha/year in Thailand-Vietnam (Landolt and Kandeler, 1987), 36-51 t/ha/year in Israel (Leng at al., 1995), 7-8 t/ha/year in Russia (FAO, 2001), 22-34 t/ha/year in Germany (Mkandawire and Dudel, 2005), 30$70 \mathrm{t} / \mathrm{ha} /$ year in India (Leng et al., 1995), >30 t/ha/year in Egypt (Landolt and Kandeler, 1987 ) and $57-185 \mathrm{t} / \mathrm{ha} / \mathrm{year}$ in various regions of the USA (FAO, 2001).

In 2001, the FAO noted that in Uzbekistan, based on macrophytes Lemna minor of the genus Lemnaceae, they can produce 7-15 t / ha / year (FAO, 2001), based on our scientific studies, it was proved that in Uzbekistan it is possible to obtain $154 \mathrm{t} /$ ha / year wet biomass or 27.34 tons of dry weight. This is due to favorable weather conditions in Uzbekistan, the fact that the number of sunny days is almost 308 days, the possibility of continued growth of macrophytes from March to November. The production of industrial products based on the Lemnaceae family is widespread, one of the main ones is duckweed flour, fatty acid-rich ingredients, various feed additives for poultry, protein feed for fish (Haustein et al., 1994; Bairagi et al., 2002). It was noted that flour made on the basis of macrophytes belonging to the genus Lemna contains $35-45 \%$ of crude protein and $7-10 \%$ of fibrillarfibers (Olorunfemi et al., 
2006; Hasan and Chakrabarti, 2009; Rojas et al., 2014). Therefore, when growing edible insects from macrophytes, the preparation of feed or feed additives and their widespread use in practice is of great scientific and practical importance.

\section{Purpose of work}

Study of the viability of Tenebrio molitor larvae (Coleoptera: Tenebrionidae) in macrophytes grown in Uzbekistan and the dynamics of their egg laying.

\section{Materials and Methods}

\section{Research methods (including equipment)}

Object of study. The sixth generation $\left(\mathrm{F}_{6}\right)$ Tenebrio molitor (Coleoptera: Tenebrionidae) was used, collected from the southern foothills of Uzbekistan and propagated under controlled conditions.

In the course of the study, from the numbered larvae and beetles of Tenebrio molitor (128: larvae 108, 20 beetles) collected from nature, after visual observation, we selected 2 largest in size compared to others (TMO-2: $5.36 \mathrm{~cm}$, TMO-6 : $4.83 \mathrm{~cm})$, ( $\mathrm{F}_{1}$ variant), on the basis of which the Tenebrio molitor colony was formed. Growing conditions: wheat bran with a standard content (protein 14-15\%, fat 0.8$1.0 \%$ ), as well as Lemna minor from macrophytes (protein $16.1 \%$, fat $2.8-3.1 \%$ ) and used the dry biomass of Azolla carolina (protein $-27.6 \%$, fat-2.8-3.2\%). Temperature $20-22^{0} \mathrm{C}$. In this study, $\mathrm{F}_{1}$-based variants of TMO-2 and TMO-6 larvae based on $\mathrm{F}_{6}$ variant were used to determine viability characteristics on various nutrient media that are produced by the protein and to study the rate of their laying. Variants of Tenebrio molitor TMO-2 and TMO-6 larvae were used as control for each other when analyzing protein formation in various nutrient sources.
The duration of cultivation in all samples was 28 days. Determination of proteins. Method R. Scoups (1985) was used for protein purification. When separating proteins, the dry mass of the insect was crushed and disinfected with hexane. $1.5 \mathrm{~g}$ of insect flour was taken and extracted sequentially in $5 \mathrm{ml}$ of water, $5 \mathrm{ml}$ of $5 \mathrm{M}$ sodium chloride, $5 \mathrm{ml}$ of absolute methanol and $5 \mathrm{ml}$ of $0.2 \mathrm{M}$ phosphate buffer (pH-8.0). Each extraction was carried out for 20 minutes.

After extraction, the solutions were centrifuged for $15 \mathrm{~min}$ at a speed of 8000 $\mathrm{rpm}$. The amount of protein in the supernatant was determined by the standard Lowry method. The calculation of statistical error, mean value, confidence intervals and standard deviations of experimental data was carried out using the computer program STATISTICA 6.0 and standard methods. The statistical significance of the results was determined using Student's t-test.

\section{Results and Discussion}

In this study, variants of TMO-2 and TMO-6 larvae based on $F_{1}$ variant obtained on the basis of $F_{1}$ were used to study the properties of protein formation in various sources of nutrients.

Variants of Tenebrio molitor TMO-2 and TMO-6 larvae were used as controls for each other in the analysis of viability characteristics in various nutrient sources. In Figure 1 shows the average protein synthesis of the larvae of the TMO-2 and TMO-6 variant obtained from the $\mathrm{F}_{6}$ generation in different nutrient sources (Fig. 1). It was observed that the larvae of the TMO-2 $\left(\mathrm{F}_{6}\right)$ variant have different levels of protein synthesis when grown in various feeds, including $30.89 \%$ in wheat bran, $38.65 \%$ in duckweed, and $31.48 \%$ in azolla. 
It was noted that when growing larvae of the TMO-6 $\left(\mathrm{F}_{6}\right)$ variant in nutrient media of the same composition, $31.15 \%$ of the protein was synthesized in wheat bran, $37.60 \%$ in duckweed, and $30.26 \%$ in azolla. According to the results of general nutrient media, $31.02 \%$ of protein synthesis in wheat bran, $38.13 \%$ in duckweed and $30.87 \%$ in azolla compared to dry matter.

According to a generalized analysis of the TMO-2 and TMO-6 variants from the Tenebrio molitor $\mathrm{F}_{6}$ generation, larvae grown on wheat bran synthesized $6.98 \%$ more protein than duckweed and $0.15 \%$ more protein than larvae grown in azolla. It was found that the larvae of the TMO-2 and TMO-6 variant grown in duckweed synthesize $6.98 \%$ more protein than wheat bran and $7.26 \%$ more protein than the larvae grown in azolla. This can be explained, first of all, by the fact that flour based on azolla and wheat bran are more difficult to break down in the body of larvae than duckweed. Secondly, this can be explained by the insufficient moisture content in the flour based on azolla and the relatively low protein content in wheat bran.

The fact that the larvae of the TMO-2 and TMO-6 variants from the $\mathrm{F}_{6}$ Tenebrio molitor generation synthesized proteins with different characteristics in different sources of nutrients suggests the need to study the viability of these larvae in these nutrient sources. The viability characteristics of the larvae of the TMO-2 variant based on wheat bran are shown in Figure 2. When the viability of TMO-2 larvae in wheat bran was studied on the basis of 300 larvae (30 of them, 10 variants), it was noted that their average viability was $72.33 \%$. The daily survival of larval variants was observed, while the average survival rate was $1.0 \%$ in the first ten days (results of 5-10 days) and a 5\% decrease on the 15th day. On the 20th day of observations, the larval survival rate was $83 \%$ and decreased by $11 \%$ between 15 and 20 days. A further decrease of $9.33 \%$ was observed between 20-25 days of observation, while the decrease was $1.34 \%$ between $25-28$ days, with an average survival rate of $72.33 \%$ in the medium. Thus, the average survival of the larvae of the TMO-2 variant in this nutrient medium was $0.72 \%$.

It was noted that the average survival of the larvae of the TMO-6 variant grown on wheat bran averaged $87.33 \%$ (Fig. 3). When analyzing TMO-6 variant larvae in the variant section, it was found that the average survival rate in the first ten days was $99 \%$ on average and decreased to $94 \%$ on the 15 th day of observation. In wheat bran, the larvae of the TMO-2 variant lost $17 \%$ viability in 20 days, while the larvae of TMO-6 lost only $7.67 \%$ over this period. The larvae of the TMO- 6 variant lost viability by $11.33 \%$ by the 25 th day of observation, while the TMO-2 variant lost viability by $26.33 \%$ at that time.

By the 28th day of observation, the larvae of the TMO-6 variant lost $12.67 \%$ of their viability, while by this time the TMO-2 variant lost $27.67 \%$ of their viability. It was also noted that in the analysis from the point of view of the internal variants of TMO-2 and TMO-6, the TMO-2 variant lost $15 \%$ more viability than the TMO-6 variant. Therefore, it can be assumed that the adaptability of each larval variant to the composition of the nutrient medium will also vary. The analysis of the nutrient medium (wheat bran) showed that the generalized average survival of the larvae of the TMO-2 and TMO-6 variants was $79.83 \%$. In wheat bran, the survival rate of larvae of the Tenebrio molitor $\mathrm{F}_{6}$ generation can be estimated at $0.79 \%$.

In Figures 4-5 show the survival rates of the larvae of the TMO-2 and TMO-6 variants obtained on the basis of the Tenebrio molitor 
$\mathrm{F}_{6}$ generation obtained on the basis of the macrophyte Lemna minor.

It was noted that the larvae of the TMO-2 variant grown on the basis of duckweed flour lost less than $4 \%$ of viability in the first 10 days of observation compared with wheat bran (Fig. 4). By the 15th day of observation, survival dropped sharply $(25.33 \%)$. It was noted that survival was $19.33 \%$ higher than that of wheat bran. It was found that the larvae of the TMO-2 variant grown in duckweed lost about $40 \%$ viability by the 20th day of observation, while the loss of survival was $23 \%$ higher than that of wheat bran. After 25 days of observation, the survival rate of TMO-2 larvae grown in duckweed was $56.33 \%$, which is $17.34 \%$ lower than the survival rate of larvae grown on wheat bran for 25 days. On the 28th day of the study, the survival rate of TMO-2 larvae grown on the basis of duckweed was $52.33 \%$, which is $20 \%$ lower than that of wheat bran (28th day).

Analysis of the larvae of the TMO-6 variant on internal variants showed a $4.33 \%$ reduction in survival in the first ten days of the study. This indicator was $3.33 \%$ higher than for the TMO- 2 and TMO-6 variants grown on wheat bran, and $0.3 \%$ higher than for the TMO-2 variant larvae grown on duckweed.

The overall survival of the larvae of the TMO-6 variant grown on the basis of duckweed was $48.67 \%$ (Fig. 5).

In addition, the viability of the larvae of the TMO-6 variant grown in azolla on the 15th day of observation was $73.0 \%, 20.0 \%$ lower than that of the larvae of the TMO-2 and TMO-6 variant grown on wheat, and $1.67 \%$ lower than the larvae of the TMO-2 variant grown in duckweed.

On the 20th day of the study, the survival rate of larvae of the TMO-6 variant grown in duckweed was $64.33 \%$, which is $23.17 \%$ lower than that of wheat bran and $4.33 \%$ higher than that of larvae of the TMO- variant 2 grown in duckweed. On the 25th day of observation, the average survival of larvae of the TMO-6 variant grown in duckweed was $61.33 \%$, which is $19.84 \%$ lower than that of wheat larvae and $5.0 \%$ higher than that of TMO- 2 grown in duckweed. In the last 28 days of the study, TMO-6 was $3.66 \%$ less viable than TMO-2 grown in duckweed. The 28-day survival rate of the TMO-6 variant was $48.67 \%$.

Duck weed showed an average viability of $50.50 \%$. This figure was $29.33 \%$ lower than the viability of the larvae of this variant in wheat bran. The fact that the viability of a duckweed-based culture medium is lower than that of wheat bran can be explained by the very low moisture content in duckweed flour.

Figures 6-7 show the daily survival of the larvae of the TMO-2 variant and the TMO-6 Tenebrio molitor $\mathrm{F}_{6}$ variant in a nutrient medium made from Azolla carolina flour.

The overall survival of larvae grown on the basis of Azolla carolina flour was $64.33 \%$ (Fig. 6). In particular, the survival of TMO-2 variant larvae was $94.0 \%$ in the first ten days of growth and $79.33 \%$ on the 15 th day of observation. This indicator was $14.67 \%$ lower than that of the larvae of the TMO-2 and TMO-6 variant grown on wheat bran, while it was found that it was $5.49 \%$ more viable than the larvae grown on duckweed. The larvae of the TMO-2 variant grown in azolla showed a survival rate of $68.0 \%$ on the 20th day of control. At the same time, it was noted that larvae grown in wheat bran showed $19.66 \%$ less viability, and larvae grown in duckweed were $6.0 \%$ more. On the 25th day of control, the larvae of the TMO-2 variant grown in 
azolla showed a viability of $64.67 \%$, viability of $16.5 \%$ lower than that of larvae grown in wheat bran, and $5.84 \%$ more than in larvae grown in duckweed. On the last day of the study, the larvae of the TMO-2 variant grown in azolla showed a survival rate of $63.37 \%$, $16.46 \%$ less than that of larvae grown in wheat bran, and $12.87 \%$ more than that of larvae grown in duckweed. The average survival of the larvae of the TMO-6 variant grown in azolla was $65.0 \%$ (Fig. 7).

While the larvae of the TMO-6 variant averaged $93.33 \%$ during the first ten days of control, $0.67 \%$ less than the larvae of the TMO-2 variant in the same period of time, $2.5 \%$ less than the larvae grown on wheat and duckweed. On the 15th day of observation, the larvae of the TMO-6 variant grown in azolla had a survival rate of $77.67 \%$, while the survival rate was $1.66 \%$ higher than that of the larvae of the TMO-2 variant, $16.33 \%$ higher than in larvae grown on wheat, and $3.83 \%$ higher than in larvae grown in duckweed.

On the 20th day of the study, larvae of TMO6 grown in azolla showed a viability of $74.67 \%, 6.67 \%$ more than the variant TMO-2, $13.0 \%$ less than the larvae grown on wheat, and $12.5 \%$ more than duckweed larvae. On the 25th day of observation, the larvae of the TMO-6 variant grown in azolla showed an average viability of $70.33 \%$. This figure was $5.66 \%$ higher than that of the larvae of the TMO-2 variant grown in azolla. It was found that the larvae of the TMO-6 variant grown in Azolla had a viability of $65.0 \%$ on the 28th day of the study, while the survival rate was $1.33 \%$ higher than that of the TMO-2 variant. It was noted that larvae grown on wheat bran showed a survival rate of $14.83 \%$ less than larvae grown on duckweed, and $14.5 \%$ higher survival rate. It is worth explaining that the survival rate of larvae grown in wheat bran is $15.5 \%$ higher than the survival rate of larvae grown in azolla, not due to the supply of protein in the sources, but due to the amount of moisture in it.

Moisture (9.58-10.12\%) in wheat bran (protein 15\%) may have served as a factor in higher viability of larvae than in azolla (protein-27\%, moisture content 8.2\%). Although duckweed flour (protein-16.1\%, humidity-4.4\%) is poorly synthesized in the body of larvae, it is $3.8 \%$ less than that of azolla, which can be explained by the fact that the survival of the larvae is lower than that of wheat and azolla.

In Figure 8 shows the viability of the larvae of the Tenebrio molitor $\mathrm{F}_{6}$ generation in cross section of the studied food sources. In particular, the larvae of the TMO-2 variant showed $72.33 \%$, the larvae of the TMO-6 variant showed a viability of $63.67 \%$ in wheat bran and an average of $79.83 \%$ in the nutrient medium. This indicates that their survival in this culture medium is 0.79 . It was found that the larvae of the TMO-2 variant grown on the basis of duckweed averaged $52.33 \%$, the larvae of the TMO-6 variant were $48.67 \%$, and the average viability by food sources was $50.5 \%$. According to this food source, the larvae have a survival rate of 0.50 . It was observed that the larvae of the TMO-2 variant grown in Azolla were 63.67\%, the larvae of the TMO-6 variant were $65.0 \%$, and the average survival for the food source was $64.33 \%$. In this food source, the larvae survival was 0.64 . 


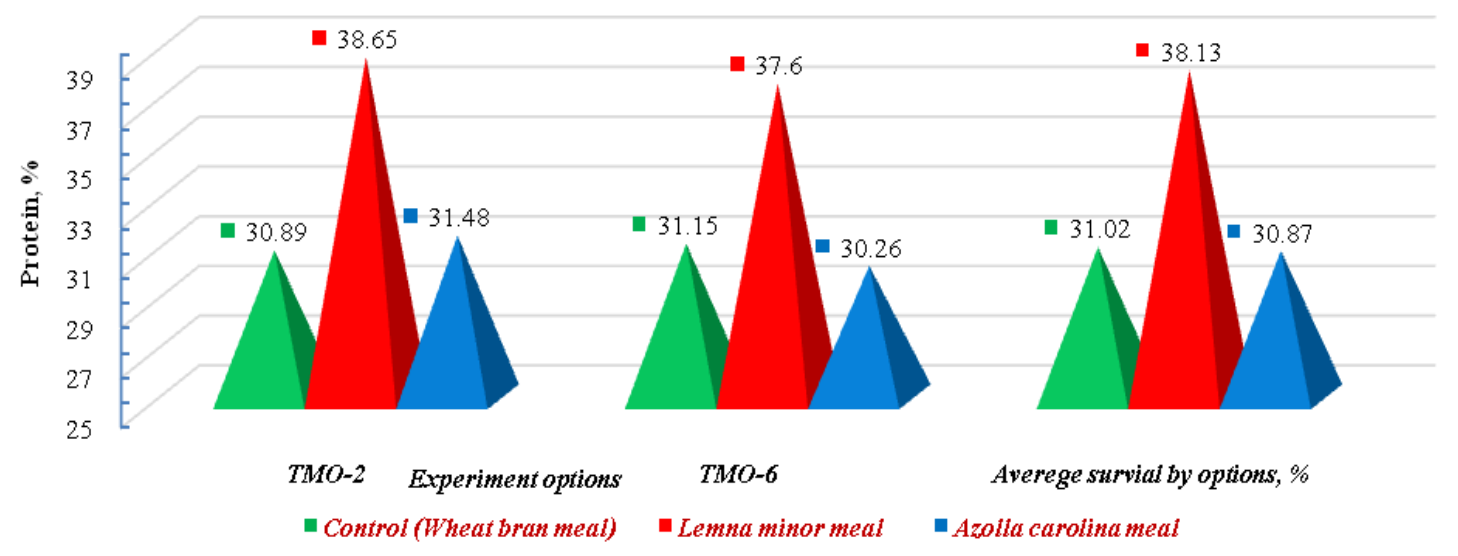

Figure.1 Protein formation of Tenebrio molitor $\left(\mathrm{F}_{6}\right)$ larvae in different nutrient content (relative to dry matter, \%)

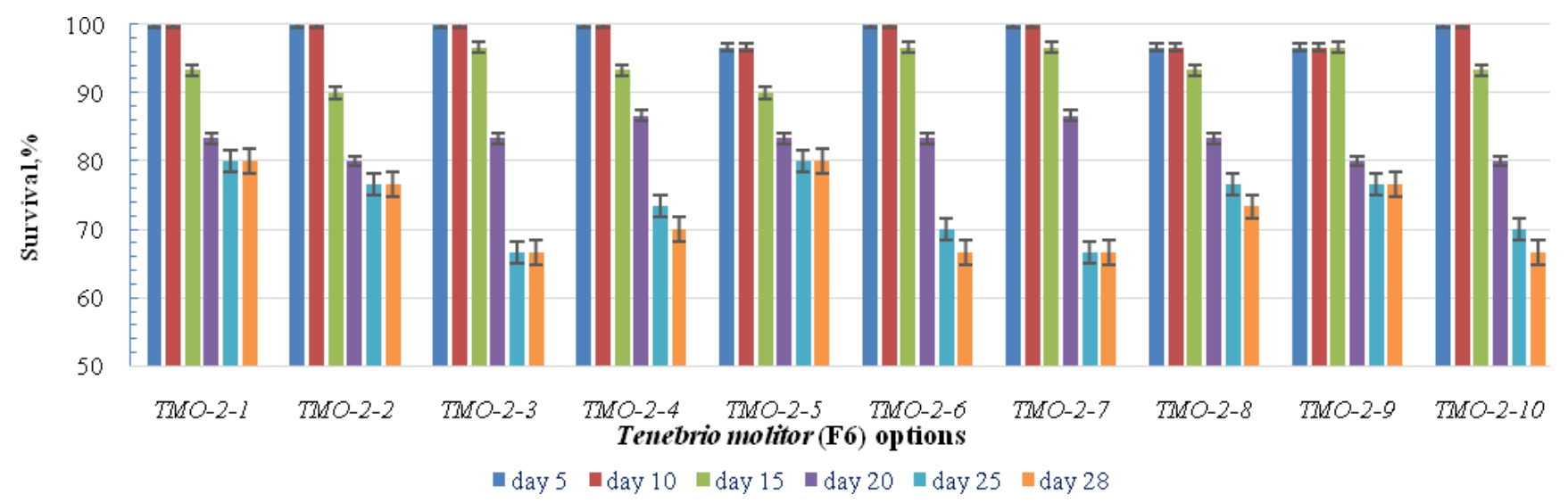

Figure.2 Survival of Tenebrio molitor larvae (TMO-2) in wheat bran (control), \%

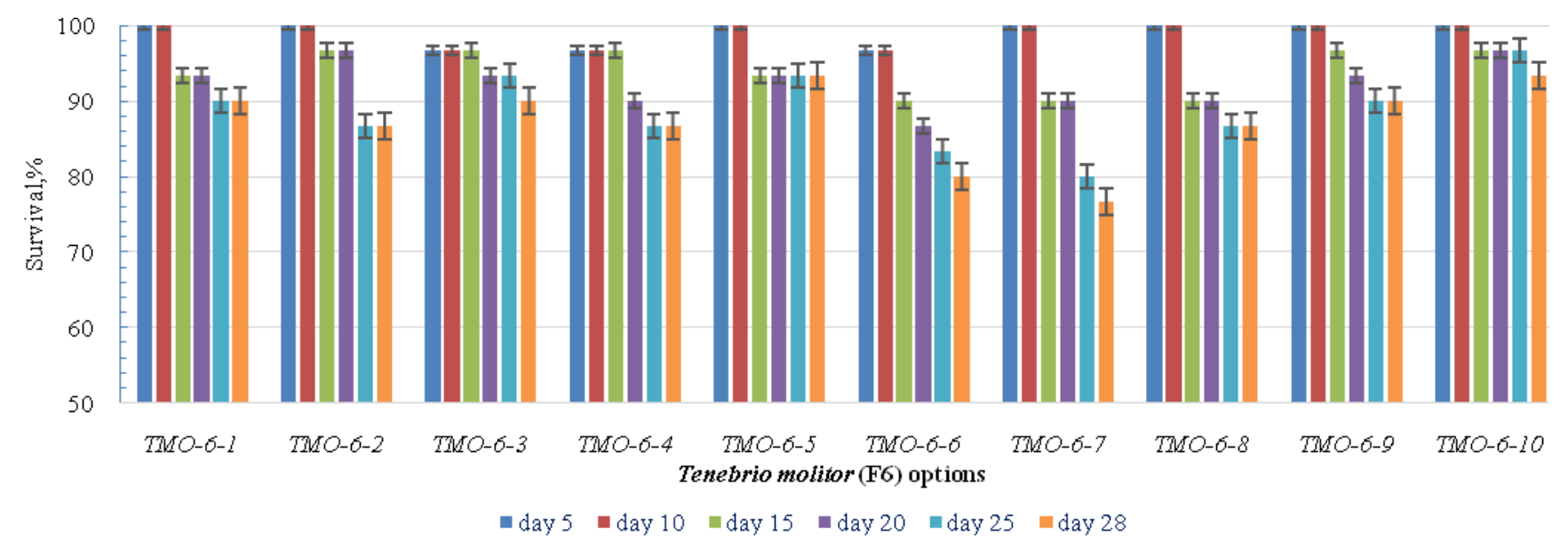

Figure.3 Survival of Tenebrio molitor larvae (TMO-6) in wheat bran (control), \% 




Figure.4 Life expectancy of Tenebrio molitor larvae (TMO-2) in Lemna minor flour, \%

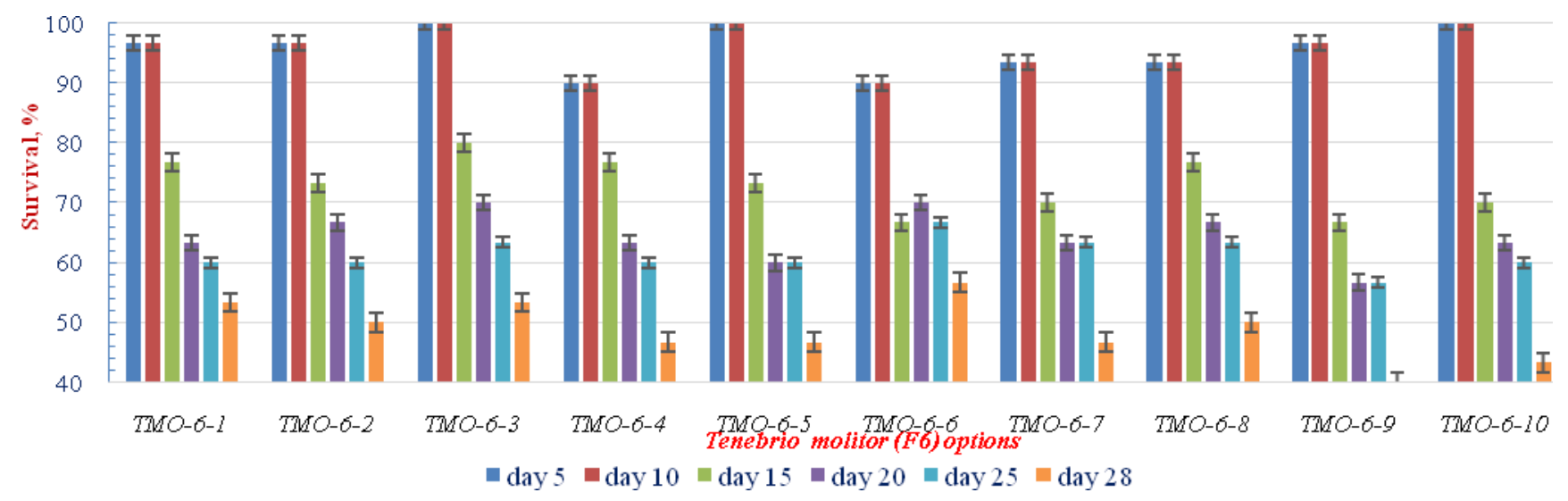

Figure.5 Life expectancy of Tenebrio molitor larvae (TMO-6) in Lemna minor flour, \%

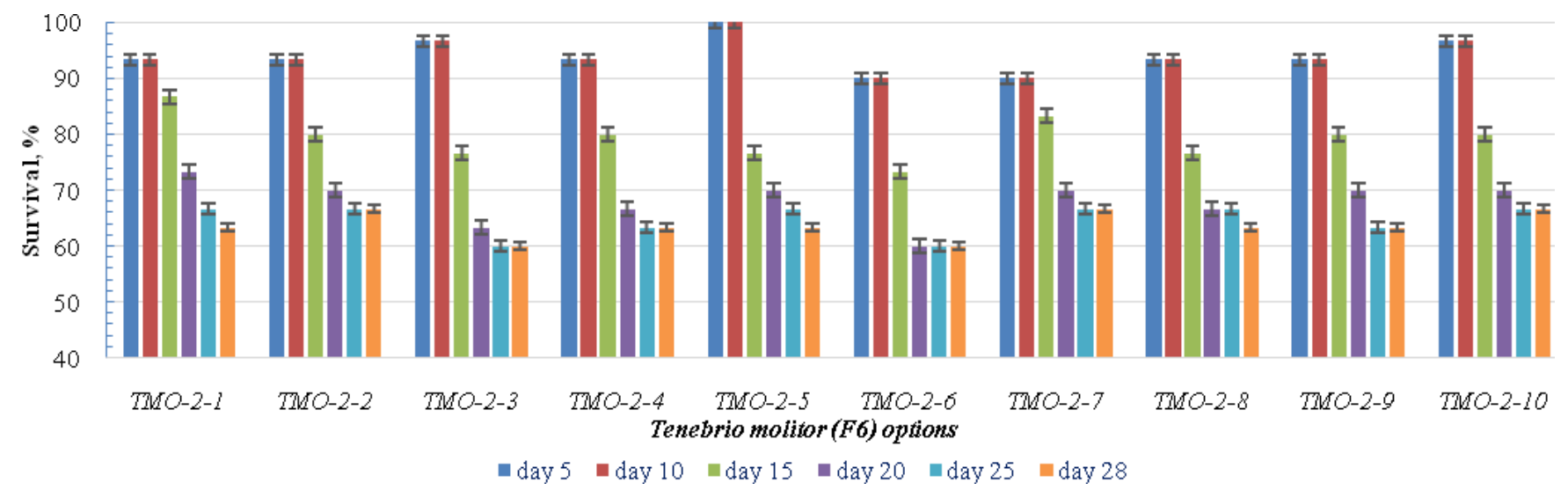

Figure.6 Survival of Tenebrio molitor larvae (TMO-2) in Azolla carolina flour, \% 


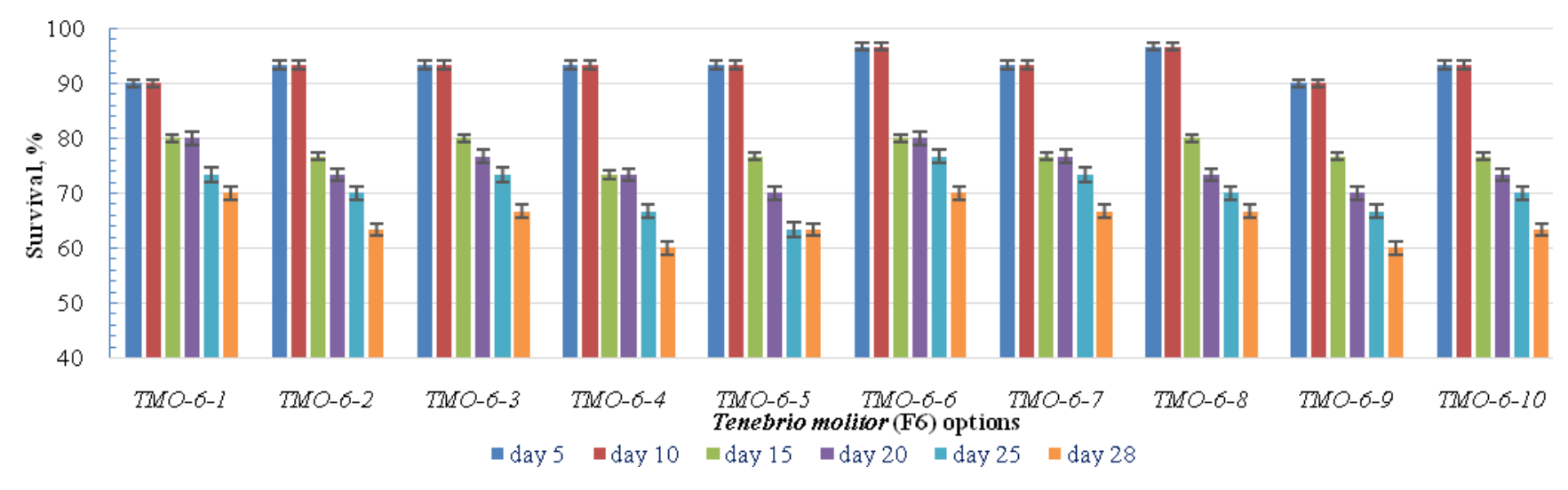

Figure.7 Survival of Tenebrio molitor larvae (TMO-6) in Azolla carolina flour, \%

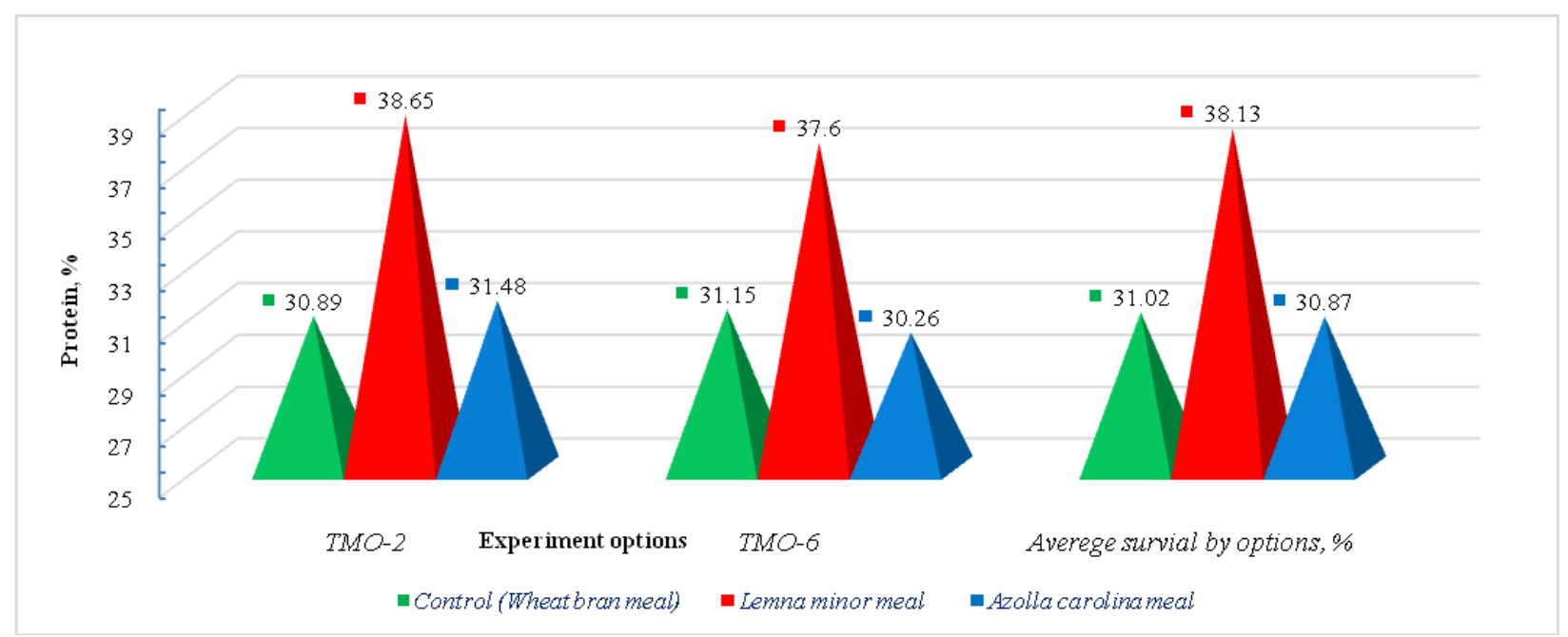

Figure.8 Survival of Tenebrio molitor $\left(\mathrm{F}_{6}\right)$ larvae in culture media

Usually in the production of Tenebrio molitor under controlled conditions and on the basis of which such expensive and inconvenient soya flour, wheat bran, corn bran, cornmeal, beer and alcohol bard, grape waste (cake) are used in the production of feed products. This suggests the need for alternative food sources to organize industrial production based on edible insects. As such alternative sources of nutrients, macrophytes can be considered as one of the most viable options. Favorable climatic conditions in the Republic of Uzbekistan, sunny days at least 270 days a year, from March to mid-November, allow macrophytes (duckweed, azolla, euchornia, pitsiya, etc.) to be grown on an industrial basis. Based on our scientific studies, it was proved that $154 \mathrm{t} / \mathrm{ha} /$ year of wet biomass or 27.34 tons of dry weight can be obtained on the basis of Lemna minor in Uzbekistan (Khujamshukurov et al., 2012). This will allow to establish the production of edible insects in Uzbekistan and provide it with a food base based on macrophytes. In our study, survival rates for Tenebrio molitor based on macrophytes in their wheat bran and macrophyte-based nutrient sources were reported. In particular, the survival rates of Tenebrio molitor $\mathrm{F}_{6}$ larvae were determined in three different moisture compositions and sources (wheat bran, Lemna minor, and Azolla carolina flour).

When the Tenebrio molitor $\mathrm{F}_{6}$ larvae of the 
TMO-2 and TMO-6 generations were grown on wheat bran, the average survival rate was 0.79 ha, duckweed 0.50, and azolla flour 0.64. Summing up the survival rates of Tenebrio molitor $\mathrm{F}_{6}$ larvae in the studied nutrient media, it was shown that the average survival was 0.96 . This allows you to create a breeding ground with a new content, high nutritional value and low cost, based on the established ratios of wheat bran, duckweed and azolla flour. As a result, the production of feed based on feed insects Tenebrio molitor will provide the fast-growing fish industry in Uzbekistan with a source of continuous, full nutritional value. Growing these types of insects using macrophytes of duckweed and azolla, which are easy to breed, will reduce their cost and increase their nutritional value.

\section{Acknowledgements}

This study was carried out as part of the scientific program of the Tashkent Institute of Chemical Technology "Development of feed production technology based on nontraditional sources".

\section{References}

Azzollini D., Derossi A., Fogliano V., Lakemond C.M.M., Severini C. 2018. Effects of formulation and process conditions on microstructure, texture and digestibility of extruded insectriched snacks. Innov. FoodSci. Emerg. Technol. 45:344-353.

Bairagi A., Sarkar-Ghosh K., Sen S.K., RayA.K.. 2002. Duckweed (Lemna polyrhiza) leaf meal as a source of feedstuff in formulated diets for rohu (Labeorohita Ham.) fingerlings after fermentation with a fish intestinal bacterium. Bioresour. Technol. 85:1724.

Berggren A., Jansson A., Low M. 2019. Approaching Ecological Sustainability in the Emerging Insects-as-Food
Industry. TrendsEcol. Evol. 34:132-138.

Bukkens S.G.F. 2005. Insects in the human diet:

Nutritional aspects. In Ecological Implications of Minilivestock (Role of Rodents, Frogs, Snails, and Insects for Sustainable Development); Paoletti, M.G., Ed.; New Hampshire, Science Publishers: New Ipswich, NH, USA. pp.545-577.

Decree of the President of the Republic of Uzbekistan, 2017, DP 2939.

Ekpo K.E. 2011. Effect of processing on the protein quality of four popular insects consumed in Southern Nigeria. Arch. Appl. Sci. Res. 3:307-326.

FAO. 2001. Duckweed: A tiny aquatic plant with enormous potential for agriculture and environment.

FoodandAgriculturalOrganization, Geneva. Pp.108.

Fitzpatrick J.J., Iqbal T., Delaney C., Twomey T., Keogh M.K. 2004. Effect of powder properties and storage conditions on the flowability of milk powders with different fat contents. J. FoodEng. 64: 435-444.

Hasan M.R., Chakrabarti R. 2009. Floating aquatic macrophytes - Duckweeds. In: M. R. Hasan and R. Chakrabarti, editors, Use of algae and aquatic macrophytes as feed in smallscale aquaculture. Food and Agric. Organ. of the U. N., Rome. p. 29-52.

Haustein A.T., Gilman R.H., Skillicorn P. W. 1994. Performance of broiler chickens fed diets containing duckweed (Lemnagibba). J. Agric. Sci. 122:285289.

Kamler E. 2012. EarlyLife History of Fish: An Energetics Approach; Springer Science \& Business Media: Berlin, Germany. Volume 4, p.72.

Khujamshukurov N.A. 2011. Alternative protein products. J. XXItechnology.4(5):14-15.

Khujamshukurov N.A., Nurmuxamedova V.Z. 2016. Production feed: modern trend and development aspect. Scientificoverview. J. Zooveterinary. 
№8 (105):34-37.

Landolt E., Kandeler E. 1987. The Family Lemnaceae: A monographic study (vol.2) Phytochemistry, Physiology, Application, Bibliography, Veroffentlichungen des Geobotanischen Institutes der ETH 1, StiftungRubel, Zurich. Pp.638.

Leng RA., StambolieJH., Bell R. 1995. Duckweed - a potential high-protein feed resource for domestic animals and fish Livestock Research for Rural Development 7.

Mkandawire M., Dudel EG. 2005. Accumulation of arsenic in Lemnagibba L. (duckweed) in tailing waters of two abandoned uranium mines in Saxony, Germany.

ScienceofthetotalEnvironment. 336:8189.

Olorunfemi T.O.S., Aderibigbe F. M., Alese B. K., Fasakin E.A. 2006. Utilization of duckweed (Lemna paucicostata) in least cost feed formulation for broiler starter: A linear programming analysis. J. Inf. Technol. 5:166-171.

Oonincx D.G., van Itterbeeck J., Heetkamp M.J., van den Brand H., van Loon J.J., van Huis A. 2010. An exploration on greenhouse gas and ammonia production by insect species suitable for animal or human consumption. PLoS ONE. Pp.144-45.

Ramos-Elorduy J., Moreno J.M., Prado E.E., Perez M.A., Otero J.L., De Guevara O.L.1997. Nutritional value of edible insects from the State of Oaxaca, Mexico. J. FoodCompos. Anal. 10:142157.

Ramos-Elorduy J., Pino Moreno J.M., Martinez

Camacho V.H. 2012. Could grasshoppers be a nutritive
meal.FoodNutr. Sci. 3:164-175.

Rojas O.J., Liu Y., H.H.Stein 2014. Concentration of metabolizable energy and digestibility of energy, phosphorus, and amino acids in Lemna protein concentrate fed to growing pigs. J. Anim. Sci. 92:5222-5229.

Rumpold B.A., Schlüter O.K. 2013. Nutritional composition and safety aspects of edible insects. Mol. Nutr. FoodRes. 57: 802823.

Smil V. 2002. Food production. In the Nutrition Transition; Academic Press: San Diego, CA, USA. Pp.25-50.

Steinfeld H., Gerber P., Wassenaar T.D., Castel V., Rosales M., Rosales M., de Haan C. 2006. Livestock's Long Shadow: Environmental Issues and Options; FAO: Rome, Italy.

Tran G., Heuzé V., Makkar H.P. 2015. Insects in fish diets. Anim. Front. 5: 37-44.

Van Huis A. 2013. Potential of insects as food and feed in assuring food security. Annu. Rev. Entomol. 58:563-583.

Van Huis A., Van Itterbeeck J., Klunder H., Mertens E., Halloran A., Muir G., Vantomme P. 2013. Edible Insects: Future Prospects for Food and Feed Security (No.171). Food and Agriculture Organization of the United Nations: Rome, Italy, 2013.

Zhao X., Vázquez-Gutiérrez J.L., JohanssonD.P., Landberg R., Langton M. 2016. Yellow mealworm protein for food purposes. Extraction and functional properties. PLoS ONE. 11, e0147791.

Zieli'nska E., Baraniak B., Kara's M., Rybczy 'nska K., Jakubczyk A. 2015. Selected species of edible insects as a source of nutrient composition. FoodRes. Int. 77: 460-466.

\section{How to cite this article:}

Mirzaeva, D. A., N. A. Khujamshukurov, B. O. Soxibov, Sh. Sh. Azimov and Kuchkarova, D. Kh. 2020. Dependence of Synthesis of Protein of Edible Insects from the Nutrient Environment. Int.J.Curr.Microbiol.App.Sci. 9(05): 3366-3377. doi: https://doi.org/10.20546/ijcmas.2020.905.400 